\title{
Determination and Comparison of Ideal and Practical Selectivity Coefficients of Membranes Containing Different Conductive Polymers
}

\begin{abstract}
A. StolarczyK*, R. Turczyn, A. Januszkiewicz-Kaleniak, W. Domagala and S. Imach
Department of Physical Chemistry and Technology of Polymers, Silesian University of Technology

Strzody 9, 44-100 Gliwice, Poland

In series of published works, usually, the ideal coefficients of selectivity is used as an indicator for separation performance of conducting polymer membranes. The main goal of the presented paper was to determine the relation between the ideal and practical selectivity coefficients of the investigated series of conductive polymer membranes, both layered and composite one, and assessed whether it is possible to rely only on the values of ideal selectivity coefficient for estimation of the membrane separation capacity. The results showed that high values of ideal membrane selectivity coefficients are necessary but not a sufficient indicator for evaluation of the real selectivity of membranes made from conducting polymers.
\end{abstract}

DOI: 10.12693 /APhysPolA.124.563

PACS: $82.39 . \mathrm{Wj}, 47.57 . \mathrm{Ng}$

\section{Introduction}

In the late 1970s the Process Technology Group at ICIs New Science Laboratory defined the process intensification strategy. One of its many definitions states that: "Any chemical engineering development that leads to a substantially smaller, cleaner, safer and more energy efficient technology is process intensification" [1]. Technologies taking advantage of membrane processes are among technologies which meet the requirements of process intensification strategy. Among others they allow decrease of the equipment-size/production-capacity ratio, energy consumption, and/or waste production, which leads to cheaper, sustainable technical solutions [2]. Nowadays only a small fraction of membrane gas separation potential applications is being used in chemical industries and refineries [3]. Membrane properties can be tailored to meet specific requirements of gas separation. During series of tests, using membranes of different materials it was investigated which tools are helpful in membrane composition designing. Conductive polymers were also used as a material for membranes preparation $[4,5]$.

In series of publications the ideal coefficients of permeability is used as indicator of membrane performance. The main goal of the presented researches was to determine whether is it possible to follow the results for the ideal coefficients of permeability during designing the composition of the membranes. It was also in the area of interest how big is a correlation between the ideal and permeability coefficients of the obtained membranes determined experimentally.

During the researches two types of membranes: composite and two-layer membranes synthesized from various components were examined.

If the gases in a mixture do not interact strongly with

*corresponding author; e-mail: agnieszka.stolarczyk@polsl.pl the membrane material, the pure gas intrinsic selectivity and the gas mixture selectivity will be equal. This is usually the case for mixtures of $\mathrm{O}_{2}$ and $\mathrm{N}_{2}$.

\section{Experimental}

\subsection{Formation of composite membranes}

Components required for formation of each membrane were synthesized according to the procedures described below. In next step membranes were cast on the Petri dish and left on a levelled table for the time necessary for the solvent evaporation. After that, the Petri dish was filled with water in order to easy recovery of the foil. Membranes were conditioned in vacuum dryer.

\subsubsection{Poly(pyrrole) in ethyl cellulose membranes $(P P Y / E C)$}

Proper amount of PPY was mixed for about $30 \mathrm{~min}$ with measured quantity of $3 \%$ solution of ethyl cellulose in toluene:etanol 60:40. The homogenous dispersion was degassed for 3 min under vacuum, due to the PPY strong air absorption.

2.1.2. Poly(aniline) in poly(styrene) membranes
(PANI/PS)

PANI/PS composites were obtained in the emulsion polymerization reaction of aniline [6].

2.1.3. Poly(thiophene) in poly(vinyl butyral) membranes (PTH/PVB)

Proper amount of $4 \%$ PTH solution and $4 \%$ PVB solution in $\mathrm{N}$-methylpyrrolidone were mixed for $30 \mathrm{~min}$ on a magnetic stirrer.

\subsection{Formation of two-layer membranes}

2.2.1. Layered PPY/poly(ethylene) membranes by in situ polymerization $(P P Y / P E)$

$1.9 \mathrm{~cm}^{3}(0.8 \mathrm{~g} ; 0.022 \mathrm{~mol})$ of concentrated hydrochloric acid was diluted in $350 \mathrm{~cm}^{3}$ acetonitrile in a $500 \mathrm{~cm}^{3}$ beaker equipped with magnetic stirrer and immersed in ice-salt bath. $1 \mathrm{~cm}^{3}$ (0.94 g; $\left.0.014 \mathrm{~mol}\right)$ of freshly distilled pyrrole was added dropwise over $10 \mathrm{~min} .6 \times 6 \mathrm{~cm}^{2} \mathrm{PE}$ foil, which was a support layer, was immersed in solution. 
Reaction mixture was cooled in ice bath to temperature not exceeding $-1{ }^{\circ} \mathrm{C}$. The next step was to add dropwise during $1 \mathrm{~h} 3.19 \mathrm{~g}(0.014 \mathrm{~mol})$ of ammonium persulfate. Polymerization reaction was carried out for $96 \mathrm{~h}$.

2.2.2. Layered poly(aniline) $\mathrm{SO}_{4} /$ poly(ethylene) membranes by in situ polymerization $\left(\mathrm{PANI}_{\mathrm{SO}_{4}} / \mathrm{PE}\right)$

Formation of layered membranes, in which a layer of PANI was applied during chemical polymerization of aniline (in situ method), was performed according to the procedure described by Riede and co-workers [7].

2.2.3. Layered poly(N-methyl pyrrole)/poly(vinyl butyral) membranes by in situ polymerization (PNMPY/PVB)

Layered PNMPY/PVB membranes were obtained by polymerization in situ, in which a layer of PNMPY was applied during the chemical polymerization of N-methyl pyrrole. $0.511 \mathrm{~g}(14 \mathrm{mmol})$ of $1 \mathrm{M}$ hydrochloric acid was dissolved in $20 \mathrm{ml}$ of deionized water in a $400 \mathrm{~cm}^{3}$ beaker placed in an ice bath and equipped with a magnetic stirrer, dropping funnel and a thermometer. $1.134 \mathrm{~g}$

(14 mmol) of freshly distilled monomer was added dropwise to the solution within $30 \mathrm{~min}$ and stirred. Then solid PVB membrane was immersed into the solution. The temperature of the reaction mixture was maintained at $0{ }^{\circ} \mathrm{C}$. The next step was to add dropwise for about $1 \mathrm{~h}$ an oxidant $-0.9 \mathrm{~g}(3.95 \mathrm{~mol})$ of ammonium persulfate previously dissolved in $15 \mathrm{ml}$ of deionized water. The polymerization process was carried out by mixing the reagents for $2 \mathrm{~h}$.

\section{Permeability measurements}

Single-gas permeation using $\mathrm{O}_{2}$ and $\mathrm{N}_{2}$, as well as synthetic air permeation $\left(21 \% \mathrm{O}_{2} / 79 \% \mathrm{~N}_{2}, 99.99 \%\right.$ purity, Linde) experiments were performed at $296 \mathrm{~K}$ using a constant pressure method on apparatus APG-1. Detailed operation of this apparatus is described in a previous work [8]. Permeate stream was directed to the HP 5890 gas chromatograph (GC) equipped with a thermal conductivity detector (TCD) and a Monosive 5A $1 \mathrm{~m}$ length column.

Permeability coefficients of PTH/PVB, PPY /EC

and PANI/PS composite membranes with different content of conjugated polymer.

\begin{tabular}{|c|c|c|c|c|c|c|c|c|c|c|c|c|c|c|c|}
\hline & & \multicolumn{8}{|c|}{$\mathrm{PTH} / \mathrm{PVB}$} & \multicolumn{3}{|c|}{$\mathrm{PPY} / \mathrm{EC}$} & \multicolumn{3}{|c|}{$\mathrm{PANI} / \mathrm{PS}$} \\
\hline & $\% \mathrm{w}$ & 3 & 6 & 9 & 12 & 15 & 20 & 25 & 30 & 3 & 5 & 10 & 3 & 5 & 10 \\
\hline $\mathrm{N}_{2}$ & $P$ [Barrer] & 21.67 & 259.72 & 90.11 & 634.10 & 943.69 & 1784.22 & 2126.41 & 3781.17 & 7.77 & 17.45 & 143.41 & 0.48 & 0.47 & 0.45 \\
\hline $\mathrm{O}_{2}$ & $P$ [Barrer] & 651.75 & 399.00 & 363.52 & 660.62 & 870.05 & 1640.81 & 2035.71 & 3597.07 & 17.42 & 27.06 & 143.56 & 0.50 & 0.50 & 0.48 \\
\hline
\end{tabular}

Permeability coefficients of layered PPY/PE and PNMPY/PVB membranes.

TABLE II

\begin{tabular}{c|c|c|c|c|c|c|c|c|c|c|c|c|c|c|c}
\hline \hline & \multicolumn{4}{c|}{ PPY/PE } & \multicolumn{1}{c}{ PNMPY/PVB } \\
\hline \multicolumn{2}{c|}{ Active layer thickness [ $\mu \mathrm{m}]$} & 0.62 & 0.86 & 1.00 & 1.30 & 1.40 & 1.46 & 52.00 & 56.00 & 58.00 & 60.00 & 61.00 & 62.00 & 69.00 & 77.00 \\
\hline $\mathrm{N}_{2}$ & $P$ [Barrer] & 2.25 & 3.05 & 2.54 & 5.90 & 4.51 & 4.28 & 0.21 & 0.13 & 0.19 & 0.23 & 0.14 & 0.17 & 0.13 & 0.15 \\
$\mathrm{O}_{2}$ & $P$ [Barrer] & 2.28 & 2.91 & 2.57 & 6.07 & 4.55 & 4.37 & 0.62 & 0.64 & 0.66 & 0.49 & 0.41 & 0.50 & 0.47 & 0.56
\end{tabular}

Permeability coefficients of layered $\mathrm{PANI}_{\mathrm{SO}_{4}} / \mathrm{PE}$ membrane.

TABLE III

\begin{tabular}{c|c|c|c|c|c|c|c|c|c|c|c|c|c|c|c}
\hline \hline & \multicolumn{10}{c}{ PANI $_{4} / \mathrm{PE}$} \\
\hline \multicolumn{2}{l|}{ Active layer thickness $[\mu \mathrm{m}]$} & 0.05 & 0.10 & 0.15 & 0.20 & 0.25 & 0.30 & 0.35 & 0.40 & 0.50 & 0.60 & 0.80 & 1.00 & 1.20 & 1.30 \\
\hline $\mathrm{N}_{2}$ & $P$ [Barrer] & 2.40 & 2.05 & 1.80 & 0.62 & 0.28 & 0.04 & 0.04 & 0.04 & 0.04 & 0.04 & 0.04 & 0.04 & 0.04 & 0.04 \\
$\mathrm{O}_{2}$ & $P$ [Barrer] & 2.60 & 2.30 & 1.80 & 1.30 & 0.90 & 0.63 & 0.64 & 0.63 & 0.64 & 0.66 & 0.63 & 0.61 & 0.63 & 0.61
\end{tabular}

\section{Results}

For all types of membranes permeability coefficients were determined experimentally. In next step the ideal membrane selectivity coefficients were calculated and the results were compared with the results obtained experimentally. Obtained results are presented in Tables I-III and in Figs. 1-3.

\section{1. $P T H / P V B$}

In the membranes containing PTH in amounts 3-9 wt\% one can observe the typical processes of mass transfer through porous membranes (adsorption, diffusion, and desorption of the component). For these membranes the differences in $\mathrm{O}_{2}$ permeability with respect to $\mathrm{N}_{2}$ in the permeate increase significantly (Table I). Also ideal membrane permeability coefficients values increase, obtaining a maximum in the value of 1.912 .
For membranes containing $12 \mathrm{wt} \%$ or more of PTH the permeability coefficients increase because of the Knudsen diffusion caused by phase separation phenomena between the PTH and PVB component.

The ratio of the kinetic diameters of nitrogen and oxygen is not equal to the selectivity coefficient. This would imply the minimal influence of polymer in the transport of gas. This effect, however, is less important than the effect of the Knudsen diffusion. Calculation showed incensement in values of the ideal membrane permeability coefficients. Unfortunately, the experimental data did not follow that trend and the values of permeability coefficients oscillated around 1.

\section{2. $P P Y / E C$}

Transport of gases in polymer matrix takes place through formed in obtained membranes micropores, lead- 


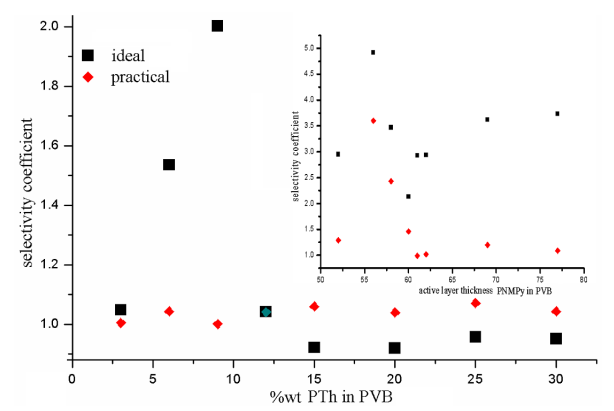

Fig. 1. Dependence of the membrane selectivity of the $\mathrm{PTH}$ in PVB and PNMPY in PVB content.

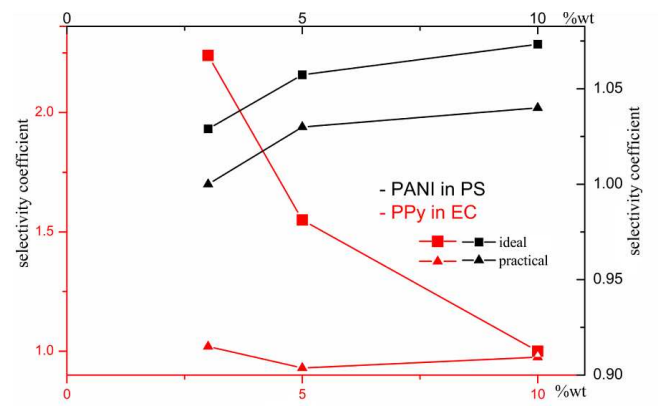

Fig. 2. Dependence of the selectivity coefficient of the $\mathrm{PPY}$ in EC and PANI in PS content.

ing to an increase of permeability coefficients and simultaneous decrease of selectivity coefficients, as presented in Fig. 2. If even a small amount of microscopic defects will be present in the membrane, the gas will be transported through these defects by means of the Knudsen diffusion. This in turn makes it impossible to study the transport properties of the polymer, because the gas uses the defects to bypass in the polymer. Therefore, the selectivity coefficient can be used to measure defects in polymer membranes. Practical selectivity coefficient is not dependent on the amount of PPY content and oscillates around 1, which indicates lack of selectivity of obtained membranes.

\section{3. $P A N I / P S$}

Addition of PANI decreases coefficients of permeability for both $\mathrm{O}_{2}$ and $\mathrm{N}_{2}$. As a result both ideal and practical membrane selectivity coefficients values increase. This indicates that polymer has an effect on gas transport through membranes. Although values of the ideal coefficient are higher, both coefficients are approximately equal to 1 , which indicates lack of selectivity of obtained membranes.

\section{4. $P P Y / P E$}

Plot of permeability coefficient as a function of the thickness of the active layer has a variable course. This can be explained by the non-uniform thickness of the active layer for various membranes. This non-uniformity of active layer is caused by the presence of many particles possessing the ability to absorb on support layer. This problem is caused by a high yield of reaction, in which

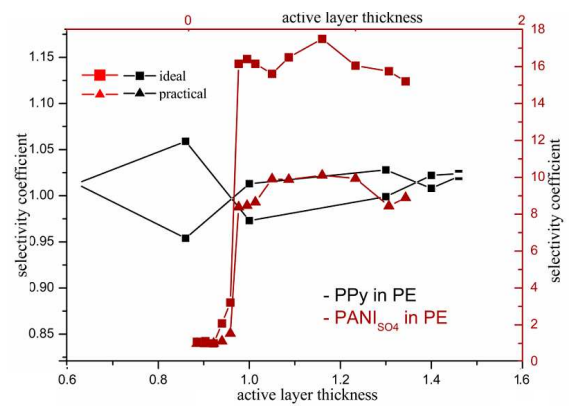

Fig. 3. Dependence of the selectivity coefficient of the $\mathrm{PPY}$ in PE and $\mathrm{PANI}_{\mathrm{SO}_{4}}$ in PE content.

hydrochloric acid was used. Values of both permeability and selectivity coefficients are close to 1 and membranes show a lack of selectivity.

\section{5. $P N M P Y / P V B$}

Permeability coefficients are independent of thickness of the active layer. Differences in their values are caused by heterogeneity of poly(N-methylpyrrole) layer. During synthesis, problem, similar to PPY/PE membrane formation, occurs. An advantage of obtained membranes is that, despite reducing the thickness of the active layer, the coefficients of selectivity slightly increased. Based on this, it is possible to assume that the thinner the membrane layer PNMPY will be characterized by higher selectivity. It can therefore be concluded that the choice of PNMPY as the active layer of membranes was right. Values of ideal and practical selectivity coefficients slightly differ from each other as shown in Fig. 1.

$$
\text { 4.6. } \mathrm{PANI}_{\mathrm{SO}_{4}} / \mathrm{PE}
$$

With the increase in thickness of the active layer there increase the values of coefficient of membrane selectivity and decrease values of permeability, especially for $\mathrm{O}_{2}$. This shows that the polymer has an effect on gas transport. Although the values of the practical coefficient grow as in the case of the ideal coefficient of membrane selectivity, they are not as high. These membranes proved to be most effective in gas separation, Fig. 3 .

For some membranes it can be observed that the permeability of $\mathrm{N}_{2}$ is higher than the permeability of $\mathrm{O}_{2}$, although it has a larger kinetic diameter. The reason may be that the $\mathrm{O}_{2}$, as diradical species, begins to interact with the conductive polymer and therefore its transportation in the membrane material is impaired. $\mathrm{N}_{2}$, which is an inert gas, does not give any additional resistance in the course of the process.

Phase separation observed in few types of membranes causes formation of defects. This significantly affects the measurement results, because gas uses pores to pass through membranes (Fig. 4).

Among the tested materials for the formation of membranes, only one, $\mathrm{PANI}_{\mathrm{SO}_{4}}$, met expectations and has demonstrated selectivity for gases. But even in this case the practical values of the coefficient did not coincide with the values of the ideal coefficient. 


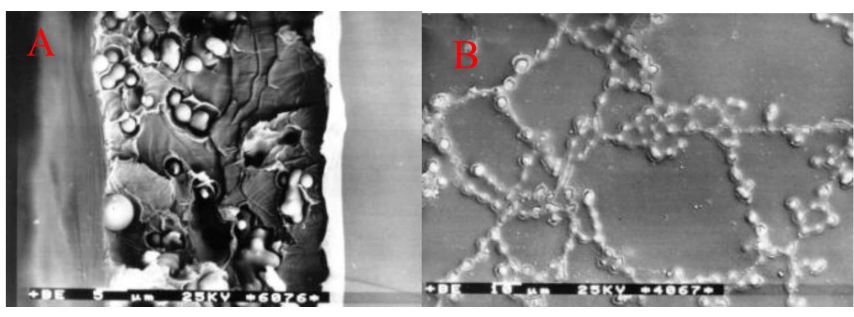

Fig. 4. Phase separation in: (left) $\mathrm{PTH} / \mathrm{PVB}$ membrane, (right) PPY/EC membrane.

\subsection{ESR spectroscopy studies}

ESR spectroscopy studies performed on a spectrophotometer RadioPan confirmed the interaction of $\mathrm{O}_{2}$ with the PANI polymer matrix. The doped PANI has unpaired electrons which can interact with $\mathrm{O}_{2}$, occuring in the triplet state with two unpaired electrons. This phenomenon could explain better PANI selectivity for $\mathrm{N}_{2}$ and $\mathrm{O}_{2}$, even though these gases have a similar kinetic diameter of the particle. ESR signals recorded during the purge of PANI with $\mathrm{N}_{2}, \mathrm{O}_{2}$ and air, and the time course of the signal during gas changing, from $\mathrm{N}_{2} / \mathrm{O}_{2}$ to $\mathrm{O}_{2} / \mathrm{N}_{2}$ are presented in Fig. 5.

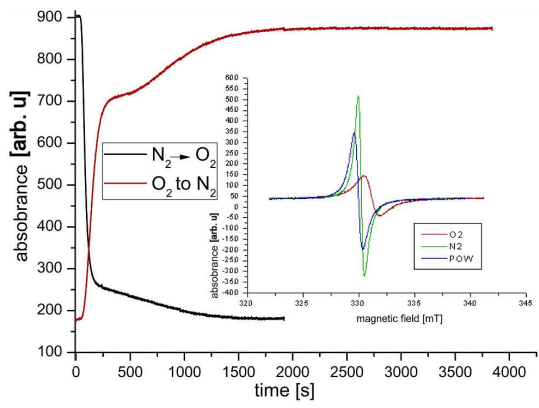

Fig. 5. ESR spectrum of $\mathrm{N}_{2}, \mathrm{O}_{2}$ and air, time course of gas exchanges. Original anion: chlorine.

As can be seen, the strongest ESR signal was observed under $\mathrm{N}_{2}$ atmosphere, and, on the other hand, the weakest in $\mathrm{O}_{2}$ atmosphere. These results confirm the proposed strong interaction of $\mathrm{O}_{2}$ molecules with PANI polymer matrix. ESR output signal under $\mathrm{N}_{2}$ atmosphere has a narrow line shape, which indicates the presence of free radicals in the polymer sample. In an atmosphere of $\mathrm{O}_{2}$ the line is visibly broadened and shifted, which is associated with the impact of free radicals of $\mathrm{O}_{2}$. It should be noted that the concentration of free radicals in the polymer matrix is constant and does not change during the measurement, and signal change is due to the interaction with $\mathrm{O}_{2}$. The intermediate result obtained for the air is also consistent with previous assumptions, because the percentage of $\mathrm{O}_{2}$ in air is $c a .21 \%$, which is intermediate between pure $\mathrm{O}_{2}$ and pure $\mathrm{N}_{2}$.

Figure 5 shows the time courses during the gas exchange: $\mathrm{N}_{2}$ into $\mathrm{O}_{2}$ and $\mathrm{O}_{2}$ into $\mathrm{N}_{2}$, respectively.
Time courses during gas exchanges: $\mathrm{N}_{2} / \mathrm{O}_{2}$ and $\mathrm{O}_{2} / \mathrm{N}_{2}$ were recorded in order to determine the rate of change of the ESR signal. Figure 5 shows a decrease in ESR signal because of $\mathrm{O}_{2}$ interaction with PANI. However, in contact with $\mathrm{N}_{2}$, it shows the opposite trend, that is, during $\mathrm{O}_{2}$ leaching, the ESR signal of the polymer will increase, because the free radicals are released from the interaction with the $\mathrm{O}_{2}$ molecules. Rates of these changes are very fast, as indicated by the practically vertical curve. Figure 5 shows that the $\mathrm{O}_{2}$ is released from the membrane material in two stages. The first stage is fast, which means that $\mathrm{O}_{2}$ undergoes physical adsorption in PANI. The second stage is slower and proves that part of $\mathrm{O}_{2}$ molecules also undergoes chemisorption in the membrane material.

\section{Conclusion}

After the studies, it can be concluded that the ideal coefficient can give only an approximate image of the situation - if the values are low, the study most probably confirms this fact. Unfortunately, even if the calculations show that the ideal coefficient is high, there exists probability that studies will not confirm that. For the best of all tested materials, i.e. $\mathrm{PANI}_{\mathrm{SO}_{4}}$, experimental results are only about half of the expected one based only on the estimated value of ideal selectivity coefficients. It can be stated that high values of ideal membrane selectivity coefficients are desirable and necessary condition but, unfortunately, in our opinion they are not a sufficient indicator to evaluate the real selectivity of the membranes. In case of strong interaction between membrane material and permeate, it should be regarded only as the first, necessary step for further detailed evaluation of membrane separation properties.

\section{Acknowledgments}

The authors acknowledge the financial support from Foundation for Polish Science grant POMOST 2011-3/8.

\section{References}

[1] D.A. Reay, C. Ramshaw, A. Harvey, Process Intensification: Engineering for Efficiency, Sustainability and Flexibility, Butterworth-Heinemann, Oxford 2008.

[2] J.C. Charpentier, Chem. Eng. J. 134, 84 (2007).

[3] P. Bernardo, E. Drioli, G. Golemme, Ind. Eng. Chem. Res. 48, 4638 (2009).

[4] A. Stolarczyk, G.K. Elyashevich, E.Yu. Rosova, M. Lapkowski, Vysokomolekularnye Soedineniya 47, 529 (2005).

[5] J. Pellegrino, Ann. N.Y. Acad. Sci. 984, 289 (2003).

[6] E. Ruckenstein, S. Yang, Synth. Met. 53, 283 (1993).

[7] A. Riede, S. Stejskal, M. Helmsredt, Synth. Met. 112, 1365 (2001).

[8] J. Podkowka, J. Izydorczyk, J. Salwinski, Polimery 34, 455 (1989) (in Polish). 